\title{
2006-2544: BRIDGING THE GAP BETWEEN ENVIRONMENTAL ENGINEERING, CHEMISTRY, AND BIOLOGY
}

\section{Alexa Rihana-Abdallah, University of Detroit Mercy}

The Author has written a number of articles published in the ASEE Annual Conference proceedings over the years. The Author teaches at the University of Detroit Mercy in the Department of Civil and Environmental Engineering. 


\title{
Bridging the Gap between Environmental Engineering, Chemistry, and Biology
}

\begin{abstract}
Recognizing the intellectual merit of interdisciplinary studies to undergraduate students, a new environmental engineering course was developed to better expose the engineering students to the world of analytical chemistry and biology. Students from the Biology and Chemistry Departments were enrolled in this course along with the environmental engineering students. The course was team-taught by three professors (including the author) from the respective departments. The course has both theoretical and laboratory components associated with it. Students were first introduced to the concept of sustainability with its three-pronged elements: social, economic, and environmental. With the increasing awareness of the potential hazards associated with the consumption of water or fish contaminated with harmful metal concentrations associated with either natural occurrence or human activities, the overarching environmental theme for this course was water quality in lakes and rivers. Following that was an introduction to the techniques of quantitative analytical instrumentation and the fundamental underlying principles of analytical chemistry. With that students gained a basic understanding of the most common methods of environmental testing, as well as the ability to discern between reliable and unreliable data. Finally, the Biology section introduced the students to the world of biota (fish and algae) and how contamination of natural resources has direct impact on the food chain. Interdepartmental teams were formed to carry out experiments designed to measure the concentrations of target contaminants in different environments. Concentrations of metals of concern in water and sediments were analyzed using a flame atomic absorption spectrophotometer. Students also set up microcosms and analyzed the metal content for algae, fish, rooted and non-rooted macrophytes. This interdepartmental collaboration helped promote environmental studies in the education of undergraduate students. As a result, students gained more fundamental understanding of instrumental analysis of contaminants in soil, water, and biota, and the effect of pollution on the entire ecosystem and its environmental sustainability.
\end{abstract}


Introduction

Historically, higher education was characteristically confined within traditional boundaries of disciplines ${ }^{1}$. The anthropologist and the historian rarely ventured into each other's realms; nor did the engineer and the biologist. Students were lumped into broad areas of scientific interest with departmentally based specialties. But with time, educators find that pushing the limits of their field takes them into new territories and that the material they teach may have in some instances much more in common with that of colleagues across the campus than with members of their own departments. The continuing appearance of new departments and new programs that merge fields, such as nanotechnology, bioinformatics, and biomechanics, is a conspicuous proof of the permeability of the lines between disciplines.

As scientists, engineers, and humanists join in addressing complex problems that must be attacked simultaneously with deep knowledge from different perspectives, students too start show increasing enthusiasm about problems of global importance that require studies through many lenses, such as pollution prevention, economic development, resource sustainability, and global climate change $\mathrm{e}^{2,3}$.

Recognizing the intellectual merit of interdisciplinary studies to our undergraduates, an environmental engineering course was designed to include more concepts and application of chemistry and biology, and to enroll students from these departments to encourage interdepartmental collaboration among students and faculty. The broader impact of this course is two-fold: a significant opportunity to promote environmental engineering studies to a diverse student body, and a more in-depth understanding of chemicals analysis and underlying biological concepts to our engineering undergraduates. Considering the approximate physical locations of all three departments and the genuine interest in environmental issues of the involved faculty, this interdisciplinary course was well suited for application at a small university such as ours.

With the increasing awareness of the potential hazards associated with the consumption of water or fish contaminated with harmful metal concentrations associated with either 
natural occurrence or human activities ${ }^{4-6}$, the overarching environmental theme for this course was water quality in lakes and rivers and its implications on the ecosystem and its sustainability.

The course was proposed to include both a theoretical and a laboratory section. First, the students are introduced to the concepts of sustainability and water quality analysis. Secondly, students learn instrumental analysis including basic principles of theory, operation, and calibration of analytical instruments, method development and assessment, data collection and analysis. In the third phase, aquatic floral and faunal assessment and quantification are presented. The concepts of bioconcentration and bioaccumulation are introduced and their health implications are discussed.

Following the theoretical section, interdepartmental teams are formed to carry out experiments designed to measure the concentrations of target contaminants in different environments.

\section{Sustainability}

A number of experts agree that in the 21 st century, development of sustainable water is a remarkable challenge and that a global water crisis is already occurring. Freshwater withdrawal has almost doubled since 1960 and nearly half the world's major rivers are going dry or are badly polluted ${ }^{7,8}$. Climate change leading to droughts and floods exasperate the situation. As water resources grow scarce, and development influences both quantity and quality of water, analysis of water parameters and target contaminants becomes the logical environmental theme of this course.

The concept of sustainability are presented and defined with its three components: social, economic, and environmental. An emphasis is put on the fact that all three types overlap and no economic system is sustainable unless it accommodates the ecosystems in which it depends. 
"Meeting the needs of the present without compromising the ability of future generations to meet their own needs" "proves challenging when agricultural runoff, animal wastes, and industrial pollution are impacting fresh waters as well as coastal waters. This in turn influences the health of the people using these waters for drinking water, irrigation water, fishing and recreation. Moreover, rising consumption rates, poor water management climate, and surface and groundwater contamination speak to the need for greater water conservation. All these issues are discussed while students develop an awareness of the true economic costs of water use. As John Briscoe, senior water advisor for the World Bank, once said, "Water is not a resource that is immune to the laws of economic thinking. As with anything cheap, people will waste it."

\section{Chemistry}

Often undergraduate environmental engineers lack the basic understanding of the most common methods of environmental testing, as well as the ability to discern between reliable and unreliable data. Exposing the students to the world of analytical chemistry is of tremendous benefit. Methods involving sampling techniques, sample preparation, techniques to separate or purify a sample, and methods to identify a pure substance or the components of a mixture are presented. Best ways to increase accuracy, selectivity, sensitivity, and reproducibility of experimental results are introduced in a very general format. The concepts of analyte and matrix are also defined. Instrumental analysis including basic principles of theory and operation of selected instruments (atomic absorption spectrophotometry, gas chromatography, and mass spectroscopy) are briefly presented. By the end of this section, it is expected that students gain a better appreciation of the meticulous effort involved in the detection, separation, identification, and measurement of chemicals in an environmental sample.

\section{Biology}

In this third component of this course, students are introduced to the aquatic floral and faunal world. A general overview of algal and macrophyte morphology, physiology, identification, and quantification of species is included. The type and distribution of algae 
and aquatic macrophytes, as well as the diversity and quantity of zooplankton, macroinvertebrates, and fish in freshwater environments serve as indicators of environmental stressors including contamination. As students acknowledge the great diversity of appearance and behavior of species in the environment, they also identify the particular adaptation of each species to environmental stressors and conditions in benthic regions. In addition, concepts of bioconcentration and biomagnification are presented. In this unit, students are expected to gain a deeper understanding of the bioaccumulation of pollutants up the food chain by transfer of residues of the substance in smaller organisms that are food for larger organisms in the chain. The sequences of processes result in an organism having higher concentrations of a substance than is present in the organism's food.

\section{Laboratory experiments}

This course concludes with a field work and a laboratory section, where students collect water samples, macroinvertebrates, and aquatic macrophytes for chemical analysis. Interdepartmental teams are formed to carry out the limnological assessment of the site conditions, data collection and analysis. Student teams are expected to design, execute, analyze, and communicate their work. The goal of this exercise is to have the undergraduates gain skills in solution preparation, instrumental measurement, calibration methods, as well as scientific data reporting in the form of laboratory notebooks, reports, and presentations.

The success of this course was clearly evident through student evaluations and comments. Although three professors team-taught the course, all lectures were uniformed and the flow of delivery was uninterrupted. After completing my section, I attended every lecture since this course was designed and offered through the Department of Civil and Environmental Engineering. Students commented on the learning experience and the benefits of closely working with students from other majors. They repeatedly stated their satisfaction with understanding the "whole picture" and touching on all aspects of environmental analysis. Typical course topics are presented in Table 1. 
Table 1. Course topics covered during the semester

\begin{tabular}{|c|l|}
\hline Week & Topic \\
\hline 1 & Introduction / Course Overview \\
\hline 2 & Sustainability \\
\hline 3 & Ecology \\
\hline 4 & Water Quality Parameters \\
\hline 5 & Effects on Ecosystem \\
\hline 6 & Analytical Chemistry \\
\hline 7 & atomic absorption spectrophotometry \\
\hline 8 & gas chromatography \\
\hline 9 & mass spectroscopy \\
\hline 10 & $\begin{array}{l}\text { Aquatic floral assessment and } \\
\text { quantification }\end{array}$ \\
\hline 11 & $\begin{array}{l}\text { Aquatic faunal assessment and } \\
\text { quantification }\end{array}$ \\
\hline 12 & Bioconcentration and Biomagnification \\
\hline 13 & Team project \\
\hline 14 & Team project \\
\hline 15 & Final Report and Presentation \\
\hline
\end{tabular}

\section{Conclusions}

The advantages and need for interdisciplinary studies at the undergraduate level have been echoed on numerous fronts. As a mode of discovery and education, interdisciplinary collaboration has delivered much already and promises more- $\mathrm{a}$ sustainable environment, new discoveries and technologies to inspire young minds, and a deeper understanding and preparedness of our graduates for professional challenges and endeavors. It helps make the higher education system of the United States one of the most remarkable system in the world. The interdisciplinary course that was designed in our department introduces the student to instrumental analysis and aquatic floral and faunal assessment in freshwater environments. It helps promote environmental studies in the education of undergraduate students. As a result, students gained more fundamental understanding of contaminant path and fate in the environment, and the effect of pollution on the entire ecosystem and its environmental sustainability. 